\title{
Unusual near- miss case of atonic postpartum haemorrhage in GMC Chandrapur (Dawn from death to life)
}

\author{
Shrirame D.V. ${ }^{1}$, Priyadarshini P. ${ }^{2}$, Waikar M.R. ${ }^{3}$ \\ ${ }^{1}$ Dr. Deepti V. Shrirame Assistant Professor, ${ }^{2}$ Dr. Preeti Priyadarshini, Assistant Professor, ${ }^{3}$ Dr. M.R. Waikar, \\ Professor and HOD, Department of Obstetrics and Gynecology, GMC Chandrapur, Maharashtra, India
}

Address for correspondence: Dr. Deepti V. Shrirame, Email: drdeeptivs@gmail.com

\begin{abstract}
A maternal near- miss is an event in which a pregnant woman comes close to maternal death, but does not die. A 8 months gestation third gravida patient was admitted in GMC Chandrapur in preterm labor with intrauterine death. It was an uneventful delivery and as she was a high risk patient for postpartum hemorrhage, all preventive measures were taken. Unfortunately she landed up in atonic PPH for which her subtotal obstetric hysterectomy was done but within one hour she landed up in cardiac arrest, was revived with CPR and her internal iliac artery ligation was done. Postoperative course was uneventful and she was discharged on $10^{\text {th }}$ postoperative day. The aim of this report is to stress the need for strict vigilance of PPH and cardiac arrest and prompt intervention involving multidisciplinary team which led to salvaging the precious life of a mother.
\end{abstract}

Keywords: Near- miss, Atonic postpartum haemorrhage, Cardiac arrest, Cardiopulmonary resuscitation, Internal iliac artery ligation

\section{Introduction}

The World Health Organization defines a maternal near miss case as" a woman who nearly died but survived a complication during pregnancy, child birth or within 42 days of termination of pregnancy" [1,2]. Near- miss events are now replacing maternal deaths as the criteria of choice for evaluating women health and quality of obstetric care as the number of maternal deaths are decreasing. Chandrapur Medical College is a busy tertiary care centrelocated in the heart of tribal area catering to the needs of patients from the Gadchiroli, Yavatmal districts and Andhra Pradesh apart from Chandrapur district. This case provides us a guiding force showing that such a complication can occur for which an emergency plan is to be kept ready and is to be implemented promptly in order to save one precious maternal life.

\section{Case Report}

A 30 year old multigravida, resident of Navin Dehli, Ballarshah was admitted in GMC Chandrapur on 19/1/17 at 10:30 am with history of 8 months amenorrhea and complaints of per vaginum bleeding since 9 pm the previous night with loss of fetal movements since two hours. She was married since 9 years, gravida3 para 2 living 2 , both males 8 and 7 years full term normal delivery. Her last menstrual period was 3/5/16 and her EDD 10/2/17. Her past, personal, family history was not significant. Her general condition was moderate, pulse $80 / \mathrm{min}$, blood pressure $-120 / 90$, pallor $3+$. Her cardiovascular and respiratory examination was within normal limits. Uterus was 34 to 36 weeks gestation, tone raised, presentation was cephalic, Fetal heart sounds were not audible, on per vaginum examination, cervix was 1 finger loose, $60 \%$ effaced, membranes were present, pelvis was adequate. Her emergency USG was done which showed intrauterine death (IUD) with intraplacental hematoma. All her investigations were sent which were within normal limits. She and her relatives were informed regarding the demise of her baby and possible serious consequences. Induction was done with artificial rupture of membranes and inj oxytocin 5 units in drip was started with injectable antibiotics. She delivered an IUD (fresh) female

Manuscript received: $25^{\text {th }}$ May 2017

Reviewed: $04^{\text {th }}$ June 2017

Author Corrected: $10^{\text {th }}$ June 2017

Accepted for Publication: $17^{\text {th }}$ June 2017 
child, weight $1.8 \mathrm{~kg}$ on $19 / 01 / 17$ at $3: 03 \mathrm{pm}$. Active management of third stage, tablet misoprost 1000 micrograms per rectum and injection oxytocin 20 units in drip at 30 drops/ min was started to prevent postpartum hemorrhage. Inspite of these preventive measures there was severe postpartum haemorrhage for which she was taken to OT and explored and decision of subtotal obstetric hysterectomy was taken and accomplished as the operating gynecologist was not conversant with internal iliac artery ligation $[3,4]$. Immediate post operative period was uneventful. Patient was shifted to ICU with constant monitoring but had a bout of per vaginum bleeding one hour later at about 9:30 pm leading to her pulse rising and BP falling with sudden respiratory distress for which she was intubated .She was immediately shifted to OT for re-exploration and urgent surgeon call was given. In OT, ECG was showing flat line suggesting that the patient was in cardio respiratory arrest (Image 1). CPR was started with chest compressions at 30:2 ratio ,inj. adrenaline 1mg i.v was given immediately and fortunately to our great astonishment and delight, the patient was revived in 10 minutes $[5,6,7,8]$ (Image 2). She was quickly re-explored and decision of bilateral internal iliac artery ligation was taken as there was intraperitoneal collection of 1 liter blood and suture line was oozing. Bilateral internal iliac artery ligation was accomplished with the help of surgeons [9]. Post operatively her spo2 was $95 \%$, pulse 94 , B.P $-130 / 80$. She was shifted to ICU on ventilator with ionotropic support in the form of inj. dopamine 400microgram in drip and inj noradrenaline $4 \mathrm{mg}$ in drip. She was transfused with total 5 pints whole blood (intraoperative 2 pints and postoperative 3 pints) and 3 Fresh frozen plasma. Gradual waning of ionotropic support was done and she was put off ventilator on $3^{\text {rd }}$ post op day. Antibiotics injection Meropenem $1 \mathrm{~g}$ i.v 12 hourly, injection metronidazole 500mg 8 hourly were continued till $7^{\text {th }}$ postoperativeday. Postoperative period was uneventful and patient was discharged on $10^{\text {th }}$ postoperative day in good health to our great satisfaction. (Image 3)

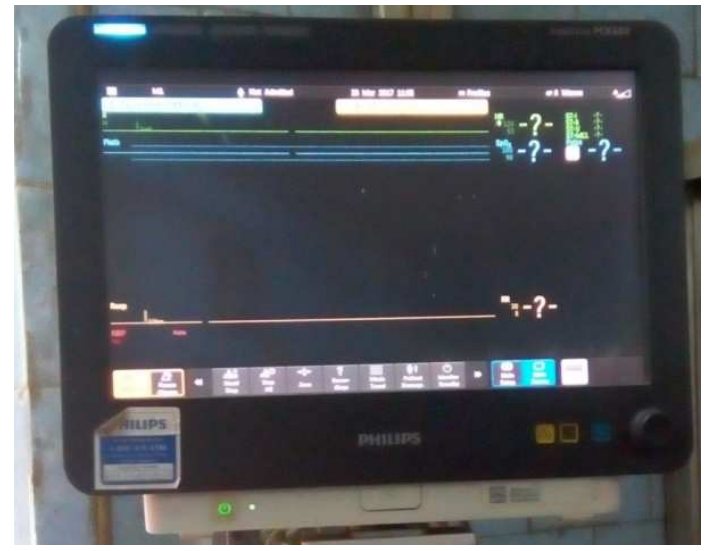

Fig 1: Cardiac arrest

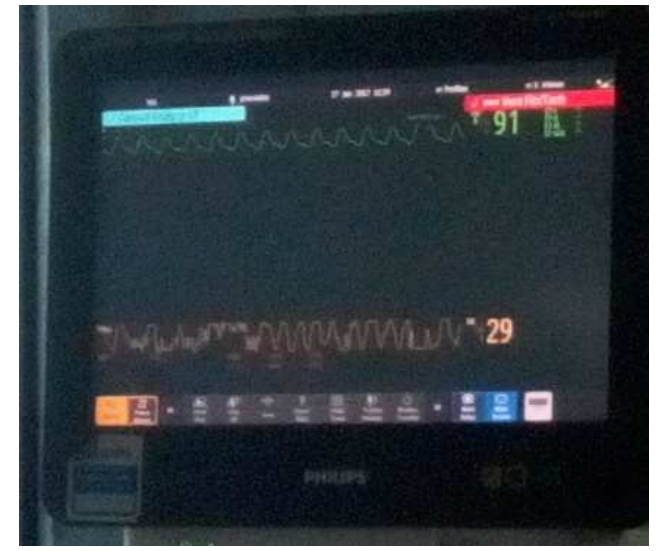

Fig 2: Recovery after treatment

\section{Discussion}

Identification Criteria for Near Miss Cases: According to the World Health Organization, if a woman present any of the conditions below during pregnancy, childbirth or within 42 days of termination of pregnancy and survives, she is considered as a maternal near miss case. $[1,2,13,14]$ Cardiovascular dysfunction (a) Shock (b)Cardiac Arrest (c) Severe Hypoperfusion (d)Severe acidosis (e) Use of continuous vasoactive drugs (f) Cardio-pulmonary resuscitation. Respiratory dysfunction (g) Acute cyanosis (h)gasping (i) Severe tachypnea (respiratory rate $>40$ breaths per minute) j)Severe bradypnoea (respiratory rate $<6$ breaths per minute) (k) Severa hypoxemia (O2 saturation $<90 \%$ for $>60$ min or
$\mathrm{PAO} 2 / \mathrm{FiO} 2<200$ ) (1) Intubation and ventilation not related to anesthesia Renal dysfunction (m) Oliguria non responsive to fluids or diuretics (n) Severe acute azotemia (creatinine $>300$ micromoles $/ \mathrm{ml}$ or $>3.5 \mathrm{mg} / \mathrm{dl}$ ) (o) Dialysis for acute renal failure. Coagulation dysfunction (p) Failure to form clots (q) Severe acute thrombocytopenia $(<50,000$ platelets $/ \mathrm{ml})$ (r) Massive transfusion ofblood or red cells (>_5 units) Hepatic dysfunction (s) Jaundice in the presence of pre-eclampsia (t) Severe acute hyperbilirubinemia (bilirubin $>6 \mathrm{mg} / \mathrm{dl}$ ) Neurologic dysfunction (u) Prolonged unconsciousness or coma lasting $>12$ hours) (v) Stroke (w) Uncontrollable fit/status epilepticus. (x) Global paralysis Uterine 
dysfunction (y) Hysterectomy due to uterine infection or hemorrhage. Our case fulfilled the criteria for near -miss case as it had cardiovascular, respiratory and uterine dysfunction. Causes of nearmiss are similar to causes of maternal deaths prevailing in the area. A systematic review to determine the causes of maternal deaths was conducted by WHO recorded wide region variation. Hemorrhage was the leading cause of maternal deaths in Africa $(33.9 \%)$ and in Asia (30.8\%) while in Latin America and the Carribean, hypertensive disorders were responsible for $25 \%$ deaths. Anemia was reported as an important cause and contributor to maternal mortality and severe maternal morbidity. Similar to the above review our near-miss case was also of hemorrhage. One maternal death completely disintegrates and weakens the whole family. Therefore such a near misscase helps us to identify our health care system lacunaes and to take appropriate corrective steps to prevent such mishap. Lessons learnt from such a near miss case serve as a useful tool in reducing MMR. Mock drill of CPR for every medical staff and acquisition of internal iliac artery ligation skill amongst the residents must be advocated. [10, 11 , $12,13,14,15,16,17]$

\section{Conclusion}

Proper monitoring, correct decision and prompt treatment are essential to prevent maternal mortality due to severe PPH for which bilateral internal iliac artery ligation is an effective armamentarium. Team work between gynecologists, surgeons, anesthesiologists, physicians and nursing staff is of utmost importance in saving the life of patient.

\section{Funding: Nil, Conflict of interest: None Permission of IRB: Yes}

\section{References}

1. Pattinson R, Say L, Souza JP, Broek Nv, Rooney C; WHO Working Group on Maternal Mortality and Morbidity Classifications. WHO maternal death and near-miss classifications. Bull World Health Organ. 2009 Oct;87(10):734.

2. Say L,Souza JP,Pattinson RC.WHO working group on Maternal Mortality and Morbidity classifications.Maternal near miss-towards a standard tool for monitoring quality of maternal health care.Best Pract Res Clin Obstet Gynaecol.2009;23(3):287-96.

3. Rossi AC, Lee RH, Chmait RH. Emergency postpartum hysterectomy for uncontrolled postpartum bleeding: a systematic review. Obstet Gynecol. 2010 Mar;115(3):637-44. doi: 10.1097/AOG.0b013e3181cfc007.

4. Mousa HA, Alfirevic Z. Treatment for primary postpartum haemorrhage. Cochrane Database Syst Rev. 2003;(1):CD003249.

5. Cardiac Arrest Associated With Pregnancy.Circulation2005;112;150-53.

6. MorrisS,StaceyM.Resuscitation in pregnancy. $\mathrm{Br}$ Med J 2003 Nov 29;327(7426):1277-92.

7. American Heart Association.ACLS Provider Manual and BLS Manual,2001.

8. Whitty JE. Maternal cardiac arrest in pregnancy. Clin Obstet Gynecol. 2002 Jun;45(2):377-92.

9. Nizard J,BarrinqueL,Frydman Fernandez H.Fertility and pregnancy outcomes following hypogastric artery ligation for severe post -partum haemorrhage.Hum Reprod.2003;18:844.

10. Khan KS, Wojdyla D, Say L, Gülmezoglu AM, Van Look PF. WHO analysis of causes of maternal death: a systematic review. Lancet. 2006 Apr 1;367(9516):1066-74.

11. Walraven G, Telfer M, Rowley J, Ronsmans C. Maternal mortality in rural Gambia: levels, causes and contributing factors. Bull World Health Organ. 2000;78(5):603-13.

12. World Health Organisation.Evaluating the Quality of Care for Severe Pregnancy Complications:The WHO Near-Miss Approach for Maternal Health.Geneva,Switzerland:World Health Organization;2011.

13.

https://en.wikipedia.org/wiki/Maternal_near_miss

14. Pragti Chhabra. Maternal Near Miss: An Indicator for Maternal Health and Maternal Care. 
Indian J Community Med. 2014 Jul-Sep; 39(3): 132-137. doi: 10.4103/0970-0218.137145

15. Taly A, Gupta S, Jain N. Maternal intensive care \& Near miss mortality in Obstetrics. Obstet Gynaecol India 2004;54:47-2.

16. Mantel GD, Buchmann E, Rees H, Pattinson RC. Severe acute maternal morbidity: a pilot study of a definition for a near-miss. $\mathrm{Br} \mathrm{J}$ Obstet Gynaecol. 1998 Sep;105(9):985-90.

17. Filippi V, Brugha R, Browne E, Gohou V, Bacci A, De Brouwere V, Sahel A, Goufodji S, Alihonou E, Ronsmans C. Obstetric audit in resource-poor settings: lessons from a multicountry project auditing 'near miss' obstetrical emergencies. Health Policy Plan. 2004 Jan;19(1):57-66.

\section{How to cite this article?}

Unusual near- miss case of atonic postpartum haemorrhage in GMC Chandrapur (Dawn from death to life). Shrirame D.V., Priyadarshini P., Waikar M.R. Int J Med Res Rev 2017;5(06):616-619. doi:10.17511/ijmrr. 2017.i06.11. 